\title{
A MEDIAÇÃO INTERCULTURAL A LUZ DA AGENDA 2030: CONTRIBUIÇÕES PARA O OBJETIVO DE DESENVOLVIMENTO SUSTENTÁVEL Nº 16
}

\author{
Renata Soares Bonavides*1 \\ Gabriela Soldano Garcez $* *^{2}$
}

Resumo: O presente trabalho (através de metodologia dialética-dedutiva, feita a partir da análise crítica de referencial bibliográfico) aborda, primeiramente, a interculturalidade, indicando conceito e importância, para, em seguida, avaliar os conflitos nascidos do interculturalismo. Após, indica o papel fundamental da mediação (como mecanismo pacífico e sustentável de solução de conflitos) para a viabilização do diálogo intercultural. Por fim, analisa a mediação intercultural como instrumento de obtenção do Objetivo de Desenvolvimento Sustentável nº. 16, da Agenda 2030, da Organização das Nações Unidas, de modo a edificar instituições resilientes e inclusivas, que proporcionem dignidade da pessoa humana para as presentes e futuras gerações.

Palavras-chave: Interculturalidade; Diálogo intercultural; Mediação intercultural; Desenvolvimento Sustentável, Agenda 2030.

\section{INTERCULTURAL MEDIATION IN THE LIGHT OF 2030 AGENDA: CONTRIBUTIONS TO THE SUSTAINABLE DEVELOPMENT GOAL 16}

Abstract: The present work (through a dialectic-deductive methodology, based on a critical analysis of bibliographic references) addresses, at first, interculturality, indicating concept and importance, and, then, assessing the conflicts born from interculturalism. After that, it indicates the fundamental role of mediation (as a peaceful and sustainable conflict resolution mechanism) in making intercultural dialogue viable. Finally, it analyzes intercultural mediation as an instrument for achieving Sustainable Development Goal 16, of the 2030 Agenda, of the United Nations, in order to build resilient and inclusive institutions that provide human dignity for present and future generations.

Keywords: Interculturality; Intercultural dialogue; Intercultural mediation; Sustainable Development, Agenda 2030.

\section{INTRODUÇÃO}

\footnotetext{
* Docente Permanente do Programa Stricto Sensu (Mestrado e Doutorado) em Direito Ambiental Internacional, na Universidade Católica de Santos. Diretora da Faculdade de Direito da Universidade Católica de Santos.

** Pós-doutora pela Universidade Santiago de Compostela/Espanha. Doutora em Direito Ambiental Internacional e Mestre em Direito Ambiental, pela Universidade Católica de Santos. Professora da Universidade Católica de Santos.
} 
O presente trabalho tem o objetivo principal de contextualizar a interculturalidade no atual cenário de globalização, partindo do pressuposto de que a diversidade cultural é uma realidade (ampliada pelo fluxo constante das comunicação, informações, tecnologias, meios de transporte, entre outras, que faz com que a interação seja ainda maior), tendo em vista que a sociedade do século XXI é plural.

Entretanto, a partir da realidade dessa convivência de diferentes povos (com identidades, religiões, costumes e hábitos diferentes), no mesmo espaço e lapso temporal, nascem conflitos sociais que são inerentes a qualquer condição humana.

Diante desse cenário, é preciso pensar em novas formas de solucionar tais conflitos para construir uma visão plural e inclusiva, baseada no diálogo intercultural, que respeite a imagem da pluralidade, mas que, ao mesmo tempo, permita o reconhecimento do outro, além da interação e da vivência em harmonia (inclusive com a "possibilidade de geração de expressões culturais compartilhadas por meio do diálogo e do respeito mútuo", conforme Convenção sobre a Proteção e Promoção da Diversidade das Expressões Culturais), evitando, assim, processos de exclusão social.

O diálogo intercultural recebe, dessa forma, fundamental importância, ao estar comprometido com a diversidade e suas diferentes formas de expressão, e também construir uma imagem da interculturalidade que promova o respeito e a convivência pacífica. Esta realidade pode ser viabilizada por instrumentos baseados nos princípios da mediação intercultural, que oportuniza a participação de todos nas discussões, debates e interações, para alcançar o consenso sobre a melhor solução para o conflito que se apresenta, o que pode contribuir, imensamente, para a satisfação de todos (que, empoderados, participam ativamente da busca por soluções), bem como da realização e/ou execução posterior do que for acordado.

Nesta linha de raciocínio, o presente trabalho aborda (com análise crítica de referencial bibliográfico de renome sobre a temática, bem como de documentos internacionais, a partir de uma visão dialética-dedutiva), primeiramente, a interculturalidade, como o conjunto de tradições, costumes, hábitos e crenças, fruto do mundo globalizado, que gera, inerentemente, o nascimento de conflitos na atual sociedade globalizada.

Esses conflitos oriundos da pluralidade, do choque entre culturas, deve ser resolvido pelo diálogo intercultural (de modo a obter novas bases de comunicação entre os envolvidos, 
de forma a torná-la respeitosa e construtiva), que pode ser promovido pelos métodos consensuais de solução de conflitos, com foco principal na mediação intercultural, que, neste trabalho, é vislumbrada como um mecanismo de ressignificação dos conflitos sociais (visando obter a harmonia, inclusão social e a pacificação permanente e sustentável).

Por fim, indica a utilização da mediação intercultural nesta sociedade plural e complexa como instrumento de cumprimento do Objetivo de Desenvolvimento Sustentável (ODS) nº. 16, da Agenda 2030, formulada pela Organização das Nações Unidas (ONU), ao “promover sociedades pacíficas e inclusivas para o desenvolvimento sustentável, proporcionar o acesso à justiça para todos e construir instituições eficazes, responsáveis e inclusivas em todos os níveis".

\section{INTERCULTURALISMO: BREVES CONSIDERAÇÕES INICIAIS}

A noção de cultura relaciona-se intrinsecamente com a experiência do indivíduo no meio em que está inserido, relacionando de que forma um determinado indivíduo está conectado a uma comunidade através de um conjunto de tradições, costumes, hábitos, crenças, práticas, conhecimentos e valores, que são passados de geração em geração, e que distingue aquele determinado grupo de outro.

Ao longo dos anos o termo "cultura" foi se modificando e somente a partir do surgimento do vocábulo inglês culture é que foi estabelecida sua acepção complexa, que abrange conhecimentos, crenças, arte, moral, leis, costumes ou qualquer outra habilidade ou tradição adquiridos pelo homem, tal como a vemos hoje (MACHADO, 2002, p. 18).

A cultura pode ser definida então, de forma bastante modesta, como a "multiplicidade de formas com que se expressam grupos e sociedade" (segundo artigo 4.1, da Convenção sobre a Proteção e Promoção da Diversidade e das Expressões Culturais) (UNESCO, 2005), ou, ainda, como "el conjunto de los rasgos distintivos, espirituales y materiales, intelectuales y afectivos que caracterizan una sociedad o um grupo social" (segundo a Conferência Internacional da Educação) (UNESCO, 1992, p. 23). Ou seja, pode ser entendida como sendo o conjunto de signos que caracterizam determinado grupo e que, a 
este, conferem identidade individual e social. É, portanto, um núcleo de identidade social de indivíduos a uma comunidade. Faz referência, portanto, aos modos de pensar, crer, sentir e atuar do indivíduo como membro de uma sociedade.

É, por esta razão, que a Conferência Internacional de Educação (promovida pela UNESCO, em 1992, sobre a temática: "La contribución de la educación al desarrollo cultural"), define cultura (no $\S 10^{\circ}$ ) como sendo: "el conjunto de signos por el cual los miembros de uma sociedade se reconocen mutuamente y se diferencian, al mismo tiempo, de los extranjeros. En esta acepción designa el ser profundo de uma colectividad, su mentalidad y su estilo de vida" (UNESCO, 1992, p. 6).

Entretanto, nas últimas décadas, com o fenômeno da globalização (que, claramente, tem encolhido as distâncias, fomentando um fluxo sem igual de comércio, informações e aproximando as pessoas ao redor do globo, numa verdadeira "aldeia global") (MCLUHAN, 1962, passim), e em razão do aumento da interdependência dos povos, a definição de cultura tornou-se um conceito estratégico para “a definição de identidades e de alteridades no mundo contemporâneo, um recurso para a afirmação da diferença e da exigência do seu reconhecimento e um campo de lutas e de contradições" (SANTOS; NUNES, 2003, p. 28).

À medida que as atividades econômicas, sociais e políticas transcendem cada vez mais as regiões e as fronteiras nacionais, isso representa um desafio direto para o princípio territorial da organização social e política moderna. Esse princípio pressupõe uma correspondência direta entre a sociedade, a economia e a organização política num território nacional exclusivo e delimitado por fronteiras. Mas a globalização rompe essa correspondência, na medida em que a atividade social, econômica e política já não pode ser entendida como tendo limites idênticos aos das fronteiras territoriais nacionais (HELD; McGREW, 2001, p.22).

A globalização consiste numa integralização do que acontece no mundo, com características de instantaneidade e velocidade, e que possui caráter polissêmico, uma vez que abrange mais de uma área. Isto é, não pode ser reduzida simplesmente a processos tão somente no setor econômico, pois abrange outras dimensões da dinâmica social cotidiana.

A globalização tem sido diversamente concebida como ação à distância (quando os atos dos agentes sociais de um lugar podem ter consequências 
significativas para "terceiros distantes"); como compressão espaço-temporal (numa referência ao modo como a comunicação eletrônica instantânea vem desgastando as limitações da distância e do tempo na organização e na interação sociais); como interdependência acelerada (entendida como a intensificação do entrelaçamento entre economias e sociedades nacionais, de tal modo que os acontecimentos de um país tem um impacto direto em outros); como um mundo em processo de encolhimento (erosão das fronteiras e das barreiras geográficas à atividade socioeconômica); e, entre outros conceitos, como integração global, reordenação das relações de poder interregionais, consciência da situação global e intensificação da interligação interregional (HELD; McGREW, 2001, p. 11).

Dessa forma, a globalização deve ser analisada como um conjunto de processos inter-relacionados em todos os campos básicos hoje existentes (como, por exemplo: político, econômico, social, educacional, tecnológico, jurídico, entre outros).

Globalization is not a specific object, instead, it is a process. Or more precisely, globalization is a set of accumulating process, resulting from and generating a dialectical whole of political, economic technological, and cultural changes. I define globalization as a multidimensional phenomenon that embodies a shift in organization of human activity and the deployment of power from a local and national orientation towards global patterns, a rising interconnectedness on a global sphere, and a rising awareness of this interconnectedness (PIERIK, 2004, p. 454/455).

Trata-se, assim, do desenvolvimento de uma nova arquitetura mundial resultado de múltiplas dimensões atuando em conjunto, que conecta todas as pessoas ao redor do mundo (fator este que foi amplamente ampliado pelos efeitos da Revolução das Comunicações, principalmente com o advento das redes sociais), fazendo desaparecer as antigas limitações de espaço e tempo entre sociedades do globo, colocando-as em constante interação, ampliando relações e atividades, além de intensificar os fluxos globais, o que cria novas possibilidades de organizações sociais (que não estão mais presas ao fator território de seus países de origem, pois encontram-se inseridas num contexto global).

Com isso, diferentes culturas permanecem em abundante contato. Sem mencionar que, esse fenômeno é intensificado pelos crescentes movimentos migratórios, que tornam a composição de cada sociedade mais complexa e plural. 
Com isso, pode-se dizer que, a sociedade do século XXI é essencialmente intercultural.

A persistência da Declaração Universal ao longo de cinquenta anos comprova de per si que, independentemente de suas origens, os valores positivos de uma cultura podem, sim, ser transferidos de boa-fé, sem violação dos cânones essenciais de cada civilização (os valores negativos, como "as histórias" demonstram, são assimilados com enorme facilidade) (ALVES, 2013, p.38).

A interculturalidade é um conceito dinâmico, que se refere as relações entre diferentes grupos de forma evolutiva, com o objetivo de fomentar o conhecimento, o respeito e o diálogo construtivo entre eles, pois tem como escopo de ir além da simples tolerância com o outro e da coexistência pacífica entre culturas. Ou seja, trata-se do conhecimento e da compreensão de diferentes culturas, mas, além disso, do estabelecimento de relações positivas de intercâmbio e enriquecimento mútuo entre os componentes culturais. (UNESCO, 1992, p. 24).

Nesse sentido, "o fundamental é sempre respeitar o outro e a comunidade nele presente como capacidade e promessa" (ALVES, 2013, p. 36).

Assim, interculturalidade pode ser definida, conforme o artigo $4^{\circ}$, item 8 , da Convenção sobre a Proteção e Promoção da Diversidade das Expressões Culturais (PLANALTO, 2007), como sendo a "existência e interação equitativa de diversas culturas, assim como à possibilidade de geração de expressões culturais compartilhadas por meio do diálogo e respeito mútuo”. Trata-se, portanto, de culturas em constante relacionamento construtivo e pacífico.

Este conceito difere-se essencialmente do multiculturalismo, que procura apenas identificar as diferenças culturais, objetivando a aceitação e tolerância entre elas, além de enfatizar "a importância do pertencimento cultural e da necessidade de que o Estado busque preservar e estimular os vínculos entre os indivíduos e seus grupos culturais" (DAMÁZIO, 2008, p. 68). 
Multicultural é um termo qualificativo. Descreve as características sociais e os problemas de governabilidade apresentados por qualquer sociedade na qual diferentes comunidades culturais convivem e tentam construir uma vida em comum, ao mesmo tempo em que retêm algo de sua identidade "original". Em contrapartida, o termo "multiculturalismo" é substantivo. Refere-se às estratégias e políticas adotadas para governar ou administrar problemas de diversidade e multiplicidade gerados pelas sociedades multiculturais (HALL, 2003, p. 52).

Ou seja, o multiculturalismo (seja na modalidade comunitarista - onde há preferência da comunidade cultural em detrimento do aspecto individual, pois, neste caso, os valores individuais somente poderão ser compreendidos quando analisados sobre o aspecto do grupo cultural ao qual o indivíduo pertence (TAYLOR, 1991); seja para os liberais - onde a diferença cultural é valorizada na medida em que traz subsídios para as escolhas individuais, pois, aqui, o indivíduo tem mais peso e importância do que o valor intrínseco da cultura tradicional, quando analisada de modo isolado (COSTA; GURZA LAVALLE, 2006), trata-se de um conceito estanque, onde um determinado elemento cultural relaciona-se apenas com os seus semelhantes, tendo somente respeito pelo outro, sem deter entre os seus objetivos principais o constante conhecimento e diálogo entre eles.

Assim, o multiculturalismo pode ser entendido como uma simples descrição de diferentes culturas dentro de um mesmo espaço territorial e lapso temporal, bem como de um projeto de reconhecimento destas diferenças entre si. Cuida de descrever, portanto, apenas "a realidade fática da presença de várias culturas no seio de uma mesma sociedade" (FORNETBETANCOURT, 2004, p. 99), sem buscar entre tais realidades efetiva integração ou conhecimento. O que leva a diversas críticas ao seu respeito, vez que possui como fundamento a tolerância (e não, a convivência respeitosa e o compartilhamento de informação e conhecimento).

Por outro lado, o interculturalismo procura ir além, visando "à superação do horizonte da tolerância e das diferenças culturais e, a transformação das culturas por processos de interação" (DAMÁZIO, 2008, p. 76).

No interculturalismo há uma relação positiva entre as sociedades e/ou comunidades. Pois, se o multiculturalismo prega apenas a constatação da coexistência pacífica das culturas (objetivando uma análise estática de respeito), o interculturalismo vai além, buscando 
relacionar as diferenças entre as sociedades, com o intercâmbio de conhecimento através do diálogo construtivo, o que permite, em última análise, uma comunicação positiva entre diferentes grupos sociais, buscando entre eles um plano de igualdade (não somente no aspecto normativo, mais também prescritivo, através da imposição de não discriminação nem desigualdade social).

A interculturalidade, diferentemente da multiculturalidade, não é simplesmente duas culturas que se mesclam ou que se integram. A interculturalidade alude a um tipo de sociedade em que as comunidades étnicas, os grupos sociais se reconhecem em suas diferenças e buscam uma mútua compreensão e valorização. O prefixo "inter" expressaria uma interação positiva que concretamente se expressa na busca da supressão das barreiras entre os povos, as comunidades étnicas e os grupos humanos (DAMÁZIO, 2008, p. 77).

É necessário, portanto, abrir o diálogo com outras formas de pensar e agir, articulando ideias e necessidades a partir do diálogo intercultural, o que é "imperativo de nosso tempo" (PANIKKAR, 2006, p. 130). Pois, não se pode fazer referência apenas ao embate entre as ideias diferentes, mas sim ao entendimento e interação com as necessidades do outro.

O diálogo intercultural é, dessa forma, uma alternativa que permite conduzir a uma efetiva transformação nos modos de pensar. Entretanto, é imprescindível que cada cidadão esteja formado na compreensão necessária para atuação na sociedade complexa atual, levando em consideração a diversidade e pluralidade existentes, com capacidade de abordar as diferentes manifestações sociais, superando o paradigma da tolerância apenas.

É, deste entendimento que surge a expressão "possibilidade de geração de expressões culturais compartilhadas" citada na já mencionada Convenção sobre a Proteção e Promoção da Diversidade das Expressões Culturais (PLANALTO, 2007), pois, ao assumir a existência de um conflito (tendo em vista diferentes universos culturais coexistindo na mesma realidade espacial), procura o desfecho mais adequado para solucioná-los, comprometendo-se com alternativas e práticas para a convivência pacífica entre as culturas, a fim de ressignificar os conflitos para que possam ser vistos sob uma ótica positiva, através da contribuição da 
superação do embate para o reconhecimento do outro e para a formação de identidade (individual e coletiva).

Para tanto, a mediação intercultural pode ser utilizada como o mecanismo de solução pacífica e adequada de tais conflitos, de forma a cumprir o Objetivo de Desenvolvimento Sustentável de $\mathrm{n}^{\mathrm{o}}$. 16, da Agenda 2030, bem como resolver a complexidade dos anseios sociais hoje existentes, através do diálogo intercultural, e que, de toda forma permita o desenvolvimento, aqui entendido como uma evolução, progresso e enriquecimento, que não pode ser medido exclusivamente pelo aumento de bens materiais, mas sim pelo melhoramento na riqueza dos seres humanos relacionada com qualidade de vida, o que, obviamente, possui uma faceta ou dimensão cultural (que se conecta ao desenvolvimento socioeconômico, tecnológico, científico, entre outros)) (UNESCO, 1992, p. 23).

\section{MÉTOdOS CONSENSUAIS DE SOLUÇÃO DE CONFLITOS: A MEDIAÇÃo COMO MECANISMO DE RESSIGNIFICAÇÃO DOS CONFLITOS SOCIAIS}

$\mathrm{Na}$ atualidade, diante da ampliação das relações sociais e a efetiva intensidade de fluxos (de pessoas, mercadorias, informações, entre outros itens indispensáveis à vida humana), os "Estados e sociedades ficam cada vez mais inseridos em sistemas mundiais e redes de interação" (GONÇALVES, 2014, p.88).

Esta realidade integra o globo numa única problemática e, consequentemente, dá origem à chamada "aldeia global" (MCLUHAN, 1962, passim), onde as fronteiras geográficas sofreram um processo de encolhimento com a ampliação das relações sociais, o entrelaçamento e a intensificação das consequências socioambientais significativas dos riscos, "de tal sorte que fatos longínquos modelam eventos locais e são por eles modelados" (AMARAL JUNIOR, 2008, p.23).

O advento da globalização fortaleceu os vínculos sociais transfronteiriços, o que reclama novas teorias que deem conta do relacionamento complexo entre a dimensão local (circunstância de co-presença) e a integração através da distância (as conexões de presença e ausência) (AMARAL JUNIOR, 2008, p.23). 
Tal realidade cria a possibilidade de novas organizações sociais, reordenação do território, e, insere determinadas comunidades num contexto global. E, diante desse fenômeno de transformação das relações de poder, é preciso disponibilizar mecanismos de cooperação a fim de solucionar os eventuais conflitos que venham a surgir com a participação de todos, em nome de uma coexistência harmoniosa.

Trata-se, portanto, da descoberta de que os conflitos desta nova sociedade multicultural podem (e devem) ser solucionados mediante o consenso, ou seja, por mecanismos consensuais (também chamados de pacíficos e inclusivos) de solução de conflitos.

Entre tais mecanismos, encontra-se a mediação, que busca, além de um meio mais adequado, por uma sensação de justiça em que as partes participam ativamente na construção da solução com a ajuda de um terceiro imparcial, que contribui para a condução de um diálogo igualitário, e também intercultural.

Pode-se vislumbrar, portanto, na mediação um meio eficaz e satisfatório para todos os envolvidos, como um desafio para obter o desenvolvimento de métodos que sejam considerados mais justos por seus usuários, a fim de propiciar um papel mais ativo através da participação de todos na construção de soluções, de modo a educar e estimular o cidadão para a autocomposição.

Essa postura de incentivo aos métodos autocompositivos permite o verdadeiro acesso à Justiça, para que se possa chegar, através de estímulos de um facilitador imparcial, a uma solução negociada mais adequada, obtendo um resultado final mais célere, eficiente e moderno, mas que, também, facilite a aproximação das partes envolvidas para que encontrem, de maneira consensual e empoderadas (pois, reconhecerão quais são seus direitos e deveres), um resultado satisfatório, que será construído em conjunto ao longo do processo de mediação, através do diálogo.

Percebe-se, portanto, que a mediação (com características de privacidade, oralidade, diálogo, autonomia, equilíbrio, celeridade, menor custo e cooperação) é um processo 
informal, voluntário, onde um terceiro interventor, neutro, assiste (a)os disputantes na resolução de suas questões. O papel do interventor é ajudar na comunicação através de neutralização de emoções, formação de opções e negociação de acordos. Como agente fora do contexto conflituoso, funciona como um catalisador de disputas, ao conduzir as partes às suas soluções, sem propriamente interferir na substância delas (CACHAPUZ, 2006, p. 30).

Com o auxílio do terceiro, as próprias partes serão auxiliadas a construir a resposta para o conflito de modo a alcançarem um acordo sobre suas adversidades, respeitando os limites legais, o que lhes confere responsabilidade sobre a decisão e a futura execução.

Isso porque, através da mediação possibilita-se solucionar o conflito de forma mais dinâmica, procurando a máxima efetividade dos direitos, além de empoderar os envolvidos na responsabilidade pela decisão e posterior execução, o que confere maior satisfação e segurança às partes, além de economia (em relação ao tempo e dinheiro), bem como contribui para o restabelecimento e manutenção das relações interpessoais.

É um processo que confere autoridade sobre si mesma a cada uma das partes. E, portanto, "que faz recair, na própria responsabilidade dos participantes, a tomada da decisão que influenciará suas vidas” (GORCZEVSKI, 1999, p. 32), fornecendo satisfação e segurança às partes, além de restabelecimento das relações pessoais.

O resultado faz mais do que meramente resolver um conflito, transforma adversários em colaboradores, estimula e vitaliza a comunicação entre os indivíduos em conflito, de modo a proporcionar aquilo que a jurisdição pública não possui condições de oferecer (devido às suas próprias características): a rapidez e a satisfação entre as partes que, dessa forma, poderão restabelecer as suas relações (MUNIZ, 2004, p. 64).

Dentro dessa realidade pacífica, quaisquer questões do cotidiano podem ser levadas à mediação, como

discordâncias entre membros de instituições de ensino ou lazer, discussões familiares e entre vizinhos e conflitos sobre o meio ambiente têm sido as principais matérias levadas à discussão através da mediação, muito embora seja permitido discutir em tal processo praticamente qualquer conflito que venha a interessar às partes (MORAIS, 1999, p. 162). 
Dentre tais questões, encontram-se aqueles conflitos oriundos da interculturalidade da sociedade plural e complexa, que podem ser resolvidos de modo mais adequado e pacífico por meio do diálogo intercultural possibilitado pela mediação (e facilitado pelo terceiro mediador), de modo a possibilitar a vivência num ambiente pacífico, de convivência solidária e respeitosa, que é condição essencial para a obtenção da dignidade da pessoa humana e qualidade de vida.

O diálogo proposto pela mediação intercultural se apresenta como um fundamento de novos tipos de relações e, nesse sentido, como alternativa à violência, aos hábitos de dominação e segregação, mas, em contrapartida, uma prática de paz, esperança e desenvolvimento, que permite recuperar memórias da pluralidade e ressignificá-las à atual sociedade.

"La paz se nos presenta, por tanto, como la esperanza de una convivencia que nos capacita para ser universales en un mundo en equilíbrio" (FORNET-BETANCOURT, 2004, p. 14).

Vale ressaltar que, esse entendimento está plenamente de acordo com o ODS 16, da Agenda 2030 para o Desenvolvimento Sustentável, que pretende construir sociedades mais pacíficas, inclusivas e sustentáveis, bem como instituições mais eficazes, responsáveis em todos os níveis (ONU, 2015).

\section{O CUMPRIMENTO DO OBJETIVO DE DESENVOLVIMENTO SUSTENTÁVEL Nº. 16, DA AGENDA 2030, POR MEIO DA MEDIAÇÃO INTERCULTURAL}

É nítido o papel fundamental, portanto, do diálogo intercultural (que pode ser promovido por mecanismos de mediação, visando solucionar os conflitos existentes) como elemento de respeito, de amizade entre nações, de valorização da própria identidade cultural, de desenvolvimento da dignidade da pessoa humana, de socialização e de promoção de outras liberdades fundamentais (como liberdade de expressão e educação), nos termos do artigo 26, item 2, da Declaração Universal dos Direitos Humanos de 1948: “A instrução promoverá a 
compreensão, a tolerância e amizade entre todas as nações e grupos raciais ou religiosos, e coadjuvará as atividades das Nações Unidas em prol da manutenção da paz” (ONU, 1948).

Somente através do diálogo é que se pode promover a capacitação de todas as pessoas a participar de uma sociedade efetivamente livre, inclusiva, inerentemente plural, onde a diversidade cultural é vista como "patrimônio comum da humanidade", de acordo com o $\operatorname{artigo} 1^{\circ}$, da Declaração Universal sobre a Diversidade Cultural (de 2002) (UNESCO, 2002).

Artigo $1^{\circ}$, Declaração Universal sobre a Diversidade Cultural - A cultura adquire formas diversas através do tempo e do espaço. Essa diversidade se manifesta na originalidade e na pluralidade de identidades que caracterizam os grupos e as sociedades que compõem a humanidade. Fonte de intercâmbios, de inovação e de criatividade, a diversidade cultural é, para o gênero humano, tão necessária como a diversidade biológica para a natureza. Nesse sentido, constitui o patrimônio comum da humanidade e deve ser reconhecida e consolidada em benefício das gerações presentes e futuras.

Isso porque, somente o diálogo intercultural permite ir além do constante relacionamento, da simples coexistência, para almejar a "instauración del conocimiento mutuo, el respeto y el diálogo entre los diferentes grupos culturales” (UNESCO, 2007, p. 18), o que é capaz de formar cidadãos abertos e disponíveis a inclusão de todas as formas de ser e pensar, o que levará à sociedades pacíficas e inclusivas, que permitam aos indivíduos viverem efetivamente juntos, desenvolvendo a compreensão do outro, através da apropriação do respeito aos valores do pluralismo e da paz, preparando cada indivíduo para enfrentar os diversos conflitos sociais com sabedoria, ou seja, o espírito de cooperação entre os diversos membros da sociedade e de seus grupos. É, afinal, o fortalecimento da personalidade e a criação de condições capazes de dar autonomia e responsabilidade pessoal a cada cidadão, praticando, assim, o sentido de identidade e de significado pessoal (UNESCO, 2007, p.19-20).

E, além disso, promover também instituições fortes, resilientes e eficazes, capazes de reduzir significativamente todas as formas de violência, proporcionando o verdadeiro sentido do Estado de Direito, fortalecer a participação, e, permitir o desenvolvimento sustentável, nos termos do Objetivo do Desenvolvimento Sustentável $n^{\circ}$. 16, e das metas: 16.1, 16.3, 16.6, 16.8, da Agenda 2030 para o Desenvolvimento Sustentável (ONU, 2015). 
Objetivo de Desenvolvimento Sustentável 16, da Agenda 2030 - Promover sociedades pacíficas e inclusivas para o desenvolvimento sustentável, proporcionar o acesso à justiça para todos e construir instituições eficazes, responsáveis e inclusivas em todos os níveis.

16.1 Reduzir significativamente todas as formas de violência e as taxas de mortalidade relacionada em todos os lugares. [...]

16.3 Promover o Estado de Direito, em nível nacional e internacional, e garantir a igualdade de acesso à justiça para todos. [...]

16.6 Desenvolver instituições eficazes, responsáveis e transparentes em todos os níveis. [...]

16.8 Ampliar e fortalecer a participação dos países em desenvolvimento nas instituições de governança global.

A Agenda 2030 para o Desenvolvimento Sustentável foi criada pela Organização das Nações Unidas (ONU), em agosto de 2015, com a necessidade de formular os novos Objetivos do Desenvolvimento Sustentável (ODS) para substituir os Objetivos de Desenvolvimento do Milênio (ODM), da Agenda 21 (também da ONU), por um novo documento internacional de mesmo caráter que se propõe a fornecer programas, ações e diretrizes com vistas ao desenvolvimento sustentável, durante o período de 2016 a 2030, formalizando, assim, o reforço pela necessidade de um novo padrão de desenvolvimento que concilie proteção ambiental, justiça social e eficiência econômica, através do consenso mundial em torno do compromisso dos países signatários pelo desenvolvimento sustentável e cooperação ambiental.

Verifica-se que, a Agenda 2030 para o Desenvolvimento Sustentável é um documento apto a definir e a implementar políticas públicas, voltadas para um planejamento participativo de toda a sociedade, que contribua para definir as prioridades do desenvolvimento sustentável a ser alcançado diante da nova realidade planetária, através de diretrizes para a cooperação em caráter multinível.

Para tanto, é composta de 17 Objetivos (subdivididos em 169 metas). Todos têm a proposta de refletir sobre os novos desafios do desenvolvimento sustentável para a atual sociedade global e do Risco (conforme expressão criada por Ulrich Beck) (BECK, 2011, passim), a fim de fornecer a dignidade.

Entre tais Objetivos encontra-se o de $n^{\circ}$. 16, sob o enfoque da promoção de sociedades pacíficas e inclusivas para o desenvolvimento sustentável, aliado ao acesso à justiça para todos e a construção de instituições eficazes, responsáveis e inclusivas em todos 
os níveis, que está relacionado diretamente ao propósito final da mediação intercultural, pois, através dela, é possível alcançar a dinâmica necessária para a construção de cidades sustentáveis, diante das múltiplas faces e das complexidades existentes na sociedade, o que, via de regra, gera conflitos de interesses que precisam ser resolvidos, só que, agora, tendo em mente a sustentabilidade das futuras gerações.

Neste sentido, a mediação tem a capacidade de instituir a promoção de diálogos entre os envolvidos (favorecendo a inclusão social), a fim de superar as tensões interculturais para a busca de soluções baseadas no consenso, tendo em vista que os passos mais importantes para uma paz sustentável, conquistada por meio da mediação, são aqueles que incentivam e reforçam as capacidades pessoais de lidar com o passado para se envolver com o presente e moldar o futuro.

Portanto, estabelecer condições para a paz sustentável significa desconstruir estruturas, situações e relações que causem conflito, e, focar na construção de estruturas, situações e relações que sustentam a paz.

Essa visão se fundamenta no fato de que, a interculturalidade não se objetiva somente "o direito dos diferentes de serem iguais, mas também o direito de afirmar a diferença" (CANDAU, 2008, p. 47). Entretanto, estes dois pontos não devem ser ditos como extremos, onde um viria a negar o outro, criando apenas conflitos (vistos de forma negativa), mas sim articulados, de modo que possam estar em paralelos, superando as desigualdades, empoderando os indivíduos para torná-los (também) mais pacíficos e, ao mesmo tempo, reconhecendo (a importância) das diferenças culturais. Esse reconhecimento deve ser feito com base no diálogo, promovido pela mediação.

"A questão está em como trabalhar a igualdade na diferença" (CANDAU, 2008, p. 49).

Assim, através da mediação intercultural, é possível alcançar a dinâmica necessária para a construção de sociedades mais inclusivas, diante das múltiplas faces e das complexidades existentes (que geram, via de regra, conflitos de interesses que precisam ser resolvidos de modo pacífico).

Desse modo, o campo de resolução de conflitos passa a ser cada vez mais instigador e desafiador, pois envolve conflitos complexos com muitas variáveis, como é o caso das 
relações interculturais. São assuntos difíceis, que extrapolam as discussões e as soluções já dispostas, e, que impõem a necessidade de outra abordagem, com novos modelos de enfrentamento, através de uma estrutura que permita a utilização de novos regimes e paradigmas para enfrentar a realidade agora existente, com instrumentos que possibilitem o diálogo (intercultural) entre todos os envolvidos, pois exige soluções integradas entre os múltiplos atores e instituições em conflito que apresentam facetas multi e interdisciplinares.

Tal realidade coaduna-se perfeitamente com a mediação e o ODS 16, da Agenda 2030, pois este visa transformar as instituições em centros mais fortes e eficazes, inclusivos, pacíficos e sustentáveis, capazes de oferecer dignidade e qualidade de vida. Isso porque, na mediação, o terceiro (isento, imparcial, neutro, capacitado) atuará visando facilitar a comunicação entre os envolvidos no conflito para que estes possam encontrar formas produtivas de lidar com a disputa, a partir do restabelecimento do diálogo. Aumenta-se, assim, a comunicação, para que possam decidir o que é melhor, buscando a harmonização e a cultura da pacificação social, atendendo as necessidades e apresentando respostas, ao promover a participação ampliada na tomada de decisões e a construção de um ambiente de paz.

Trata-se, portanto, de um modelo construtivo e cooperativo de solução, que permite o desenvolvimento de novas bases de comunicação (abertas e inclusivas); exige integração, respeito e diálogo entre todas as esferas envolvidas e, que, em última análise, é uma chave facilitadora para o fomento de um discurso de promoção dos Direitos Humanos (pois, permite o reconhecimento, a inclusão social e a conscientização sobre o outro, além do fomento ao respeito por diferentes culturas).

Assim, a mediação intercultural é aliada da conscientização para a interculturalidade, de modo a viabilizar a construção da imagem da pluralidade.

\section{CONCLUSÃO}

A mediação intercultural tem função social (de fundamental importância) inerente de criar mudanças significativas para contribuir com o surgimento de uma sociedade mais justa, inclusiva e pacífica, pois a interculturalidade não pode ser representada de forma negativa (sempre apenas como um problema a ser solucionado). 
A construção da imagem do "outro" depende de diálogo pacífico e inclusivo, que pode ser proporcionado pela mediação intercultural, vez que esta é, na atualidade, um dos principais difusores da imagem do respeito da inclusão pela pluralidade, sendo capaz de construir as representações das diferentes culturas de modo inclusivo, contribuindo para o desenvolvimento de valores e de concepções de mundo.

Dessa forma, a mediação não pode ser vista apenas como um espaço que possibilita a interação, mas também como espaço de paz constante e sustentável, um lugar onde se elabora e difunde valor, discursos e identidades, como uma força capaz de organizar sentido a fim de obter o ODS 16, da Agenda 2030, criando visões e interações positivas sobre o conflito ao propiciar um discurso de inclusão (e não de segregação e violência).

Trata-se de um espaço aberto às experiências de interculturalidade, pois, somente através desta, é que que haverá a possibilidade de ir além da simples convivência pacífica, logrando um modo evolutivo das sociedades multiculturais, por meio da instauração do conhecimento mútuo, respeito e diálogo entre os diferentes grupos.

Percebe-se, portanto, um papel de promoção da cidadania, de modo a permitir que cada indivíduo compreenda o mundo que os cerca com uma visão compromissada com a Justiça, as diferentes formas de expressão e de contexto social, o que permite o entendimento e a solidariedade entre os indivíduos, bem como a solução dos conflitos (de forma positiva tornando-se parceiros para a implementação da decisão pactuada em conjunto) existentes na atual sociedade pluralista, modificando a realidade em que estão inseridos ao compartilhar experiências, conhecimentos e ideias.

Nesse contexto, a mediação intercultural tem caráter essencial no que se refere a promoção do diálogo para a interculturalidade e para o progresso dos Direitos Humanos, ao mesmo tempo em que cria um ambiente propício às instituições mais eficazes, resilientes, sustentáveis e inclusivas, de acordo com o ODS 16, da Agenda 2030.

\section{REFERÊNCIAS BIBLIOGRÁFICAS}

ALVES, José Augusto Lindgren. Os Direitos Humanos na pós-modernidade. São Paulo: Editora Perspectiva, 2013. 
AMARAL JUNIOR, Alberto. A solução de controvérsias na OMC. São Paulo: Atlas, 2008.

BECK, Ulrich. Sociedade de risco: Rumo a uma outra modernidade. São Paulo: Editora 34, 2011.

CACHAPUZ, Rozane da Rocha. Mediação nos conflitos \& Direito de Família. Curitiba: Juruá, 2006.

CANDAU, Vera Maria. Direitos humanos, educação e interculturalidade. In Revista Brasileira de Educação. V. 13, n. 37, jan./abr. 2008. Rio de Janeiro: ANPED, 2008.

COSTA, Sérgio; GURZA LAVALLE, Adrián. Cohésion social y coexistencia intercultural em América Latina. In COTLER, Julio (ed.): La cohésion social en la agenda de América Latina y de la Unión Européa. Lima: Instituto de Estudios Peruanos, pp. 247-279.

DAMÁZIO, Eloise da Silveira Petter. Multiculturalismo versus Interculturalismo: por uma proposta intercultural do Direito. In Revista Desenvolvimento em Questão. Ano 6, nº 12. Ijuí: Editora Unijuí, julho/dezembro de 2008.

FORNET-BETANCOURT, Raúl. Filosofar para nuestro tiempo en clave intercultural. Verlag Mainz: Aachen 2004. Disponível em: <https://red.pucp.edu.pe/ridei/files/2011/08/601.pdf>. Acesso em: 25 de agosto de 2020.

GONÇALVES, Alcindo. Governança Global e o Direito Internacional Público. In: JUBILUT, Liliana Lyra (org.). Direito Internacional Atual. São Paulo: Elsevier, 2014.

GORCZEVSKI, Clovis. Formas alternativas para resolução de conflitos: a arbitragem no Brasil. Porto Alegre: Livraria do Advogado, 1999.

HALL, Stuart. A questão multicultural. In Da diáspora. Belo Horizonte: Editora UFMG, 2003.

HELD, David; McGREW, Anthony. Prós e Contras da Globalização. Rio de Janeiro: Zahar, 2001 .

MACHADO, Cristina Gomes. Multiculturalismo: muito além da riqueza e da diferença. Rio de Janeiro: DP\&A, 2002.

MCLUHAN, Marshal. The Gutenberg Galaxy. Canada: University of Toronto Press, 1962. 
MORAIS, José Luis Bolzan de. Mediação e arbitragem: alternativas à jurisdição. Porto Alegre: Livraria do Advogado, 1999.

MUNIZ, Deborah Lídia Lobo. A mediação como facilitadora do acesso à justiça e ao exercício da cidadania. In: Revista Jurídica da UniFil, ano I, n.1. Londrina: Centro Universitário Filadélfia - UniFil, 2004.

PANIKKAR, Raimon. Decálogo: cultura e interculturalidad. In Cuadernos Interculturales. Ano 4, $\mathrm{n}^{\mathrm{o}}$. 6, primeiro semestre de 2006, pp. 129-130. Chile: Universidade de Valparaíso, 2006. Disponível no site: 〈http://www.redalyc.org/articulo.oa?id=55200607>. Acesso em: 25 de agosto de 2020.

PIERIK, Roland. Globalization and Global Governance: A Conceptual Analysis. In HEERE, W. P. Heere (org.). Government to Governance: The Growing Impact of Non-State Actors on the International and European Legal System. Cambridge: Cambridge University Press, 2004.

PLANALTO. Decreto 6.177, de $\mathbf{1}^{\circ}$ de agosto de 2007 - Promulga a Convenção sobre a Proteção e Promoção da Diversidade das Expressões Culturais. 2007. Disponível em: <http://www.planalto.gov.br/ccivil_03/_ato2007-2010/2007/decreto/d6177.htm>. Acesso em: 25 de agosto de 2020.

ONU (ORGANIZAÇÃO DAS NAÇÕES UNIDAS). Declaração Universal dos Direitos Humanos. 1948. Disponível em: <https://nacoesunidas.org/direitoshumanos/declaracao/>. Acesso em: 26 de agosto de 2020.

- Transformando Nosso Mundo: a Agenda 2030 para o desenvolvimento sustentável, 2015. Disponível em: <https://nacoesunidas.org/pos2015/agenda2030/>. Acesso em: 26 de agosto de 2020.

SANTOS, Boaventura de Sousa. NUNES, João Arriscado. Introdução: para ampliar o cânone do reconhecimento, da diferença e da igualdade. In SANTOS, Boaventura de Sousa (Org.). Reconhecer para libertar: os caminhos do cosmopolitismo multicultural. Rio de Janeiro: Civilização Brasileira, 2003.

TAYLOR, Charles. The Ethics of Authenticity. Cambridge, Mass: Harvard University Press, 1991. 
UNESCO (ORGANIZAÇÃO DAS NAÇÕES UNIDAS PARA A EDUCAÇÃO, A CIÊNCIA E A CULTURA). Conferencia Internacional de Educacion - 43 a reunión. 1992. Disponível em: 〈http://www.ibe.unesco.org/sites/default/files/REC_78_S.pdf>. Acesso em: 25 de agosto de 2020.

Convención sobre la protección y la promoción de la diversidad de las $\begin{array}{llll}\text { expresiones } & \text { culturales. } & \text { Disponível }\end{array}$ $<$ http://www.unesco.org/new/es/culture/themes/cultural-diversity/cultural-expressions/theconvention/convention-text>. Acesso em 26 de agosto de 2020.

Declaração Universal sobre a Diversidade Cultural. 2002. Disponível em: < http://www.unesco.org/new/fileadmin/MULTIMEDIA/HQ/CLT/diversity/pdf/declaration_cul tural_diversity_pt.pdf>. Acesso em: 26 de agosto de 2020.

Directrizes de la UNESCO sobre educación intercultural. Paris: UNESCO, 2007. 